\title{
Pervivencias del termalismo y el culto a las aguas en época visigoda hispánica
}

\author{
ISABEL VeLAzQuez Soriano * \\ GISELA RIPOLL LÓPEZ **
}

El tema que se nos ha encargado presentemos a esta mesa redonda ha sido poco estudiado por los investigadores, y nosotros aquí sólo haremos un pequeño estado de la cuestión sobre qué vías pueden seguirse para su investigación presentando una serie de hipótesis que deben ser confrontadas con la arqueología y el estudio de los textos.

Existen muchos casos de continuidad y quizá los más ejemplares los encontremos en Italia. El primero de ellos es el de las termas de Caracalla en Roma construidas entre los años 212 y $217 \mathrm{~d}$. C., que fueron restauradas sucesivamente bajo los mandatos de Aureliano, Diocleciano e incluso el ostrogodo Teodorico. El funcionamiento de las termas se mantuvo hasta el año $537 \mathrm{~d}$. C., momento en que se realiza el fraccionamiento de los acueductos, por parte de Vitiges ${ }^{1}$.

Otro caso de continuidad termal en época tardía también en Italia es el de Vada Volaterana (Vada, Rosignano Marittimo, Livorno). Se trata de un edificio comercial y termal, articulado junto al puerto, en la localidad actual de $S$. Gaetano. El conjunto se puso en funcionamiento a principios de la época imperial y perduró hasta los siglos v-vı d. C., con una cierta seguridad hasta entrado éste último ${ }^{2}$.

En el caso hispánico, la situación es algo diferente y se ha partido, como en otras áreas, de afirmaciones erróneas del tipo de la que sigue:

* Departamento de Latín, U.C.M.

** Departamento de Prehistoria e Historia Antigua, UNED.

- Pasquinucci, Marinella, (edit.), Terme romane e vita quotidiana, Catálogo de la exposición. Módena 1987, pág. 74.

${ }^{2}$ Pasquinucci, Terme romane e vita quotidina, Op. cit., págs. 118 y 121. 
«Haremos un paréntesis para exponer que después de la dominación romana, los godos proscribieron el uso de los baños por creer que enervaban las fuerzas físicas que constituian entonces la principal dote de los hombres de todas las clases de la sociedad, prohibición que se repitió en tiempos de Alfonso VI de Castilla por cuya razón o se mandó expresamente destruir los baños romanos, debido al odio de los godos, o quedaron éstos abandonados a sí mismos, y se fueron arruinando con el tiempo" ${ }^{3}$. Dejamos de lado cualquier comentario, puesto que ya entra dentro de la historiografía.

Para realizar un análisis de la situación en la Hispania visigoda, podemos recurrir, como punto de partida, a la búsqueda de elementos de pervivencia y continuidad en los textos de la época. En ellos cabe distinguir dos aspectos diferentes; en primer lugar, la presencia de referencias al culto a las aguas, desde la concepción misma de este elemento de la naturaleza como regenerador e imprescindible para el desarrollo de la vida hasta la mención de aguas termales, lagos, etc., existentes en múltiples lugares del mundo entonces conocido, cuyo testimonio refleja la tradición literaria y los conocimientos heredados del mundo grecolatino, pudiéndose, entonces hablar tan sólo de un valor de continuidad del mundo clásico en este aspecto concreto dentro del amplio ámbito del estado de la cultura en la época a la que nos referimos. En segundo lugar las referencias a situaciones concretas del momento, desde la pervivencia de tradiciones que pueden considerarse vigentes aún en esta época hasta las referencias a construcciones relacionadas con el mundo de lo que podríamos denominar en sentido genérico «la cultura del agua», y que hay que poner en conexión con los testimonios que ofrece la arqueología.

Dentro del primer aspecto que hemos comentado el punto de partida bien puede ser el de las Etimologías de Isidoro de Sevilla, obra magna de recopilación del saber heredado en su tiempo y de transmisión del mismo, a la vez que testigo inapreciable del mundo en el que vive y escribe su autor Isidoro de Sevilla.

En el libro XIII de la citada obra, titulado De mundo et partibus, Isidoro comienza a hablar del agua y la diversidad de aguas, mares, océanos, ríos, etc., anteponiendo unas palabras sobre el nombre del agua y el valor de ésta como elemento imprescindible para el desarrollo de la vida, así como su valor purificador:

\footnotetext{
3 Sanabria Escudero, M., «La medicina emeritense en las épocas romana y visigoda», Revista de Estudios Extremeños, XX, 1964, pág. 72.
} 


\begin{abstract}
"Aqua dicta quod superficies eius aequalis sit; hinc et aequor appellatum, quia aequaliter sursum est, 2 Duo autem ualidissima uitae humanae elementa ignis et aqua; unde grauiter damnantur quibus ignis et aqua interdicitur. 3. Aquarum enim caelum temperant, terram fecundant, aerem exhalationibus suis incorporant, scandunt in sublime et caelum sibi uindicant. Quid enim mirabilius aquis in caelo stantibus? 4. Parum sit in tantam peruenisse altitudinem; rapiunt et secum piscium examina; effusae omnium in terra nascentium causa fiunt. fruges gignunt, arbores, frutices herbasque produnt, sordes detergunt, peccata abluunt, potum cunctis animantibus tribuunt" ${ }^{4}$.
\end{abstract}

En el capítulo siguiente realiza una serie de menciones de aguas, lagos, fuentes, recogiendo tradiciones conocidas anteriormente a través de textos de Plinio, Séneca, Ovidio, y otros, que, sin duda, Isidoro conoce, directa $o$ indirectamente, en las que se pone de manifiesto el carácter curativo y el poderoso efecto de las aguas sobre las personas. No hay en este pasaje una sola referencia a fuentes o lagos de Hispania, sin embargo, Isidoro se muestra como un transmisor de conocimientos aprendidos, que le merecen el mayor crédito. No pone en duda ninguna de las cualidades atribuidas a estos lugares; incluso en el último punto, después de haber hecho referencia a diversas partes del mundo conocido, expresa una generalización sobre la existencia de aguas termales, sobre las que ofrece una justificación lógica de las mismas (XIII 13, 11):

«lam uero in multis locis aquae manant perpetim feruentes, tanta ui ut balnea calefaciant. Quaedam enim terrae sunt quae multum sulphuris et aluminis habent. Itaque cum per uenas calentes aqua frigida uenit; uicino sulphuris calore contacta excandescit, nec talis ab origine effluit, sed permutatur dum uenit. Sulphur enim alumenque secum ferunt aquae; utramque materiam igne plena minimisque motibus incalescentem».

Entre los diferentes pasajes a la diversidad de las aguas, menciona una serie de ellas que tienen propiedades curativas. Las aguas de Albula, cerca de Roma, que sanan las heridas ${ }^{5}$, las de la fuente Cicerón, que sana las heridas de los ojos... En Campania hay unas aguas que curan la esterilidad de las mujeres y la locura de los hombres, mientras que la fuente Roja de Etiopía vuelve loco al que bebe de ella. La fuente Leino, de Arcadia, impide que se produzcan abortos... En Cerdeña existen fuentes termales que sanan los ojos, a la vez que descubren a los ladrones,

\footnotetext{
4 Sevilla, Isidoro de, Etimologías. Oxford, ed. Lindsay, 1911 (reed. 1966).

${ }^{5}$ Ctr. Plin. Hist. Nat. 31,10 y Sèneca, Nat. Quaest, 3, 20, 4.
} 
«pues con la cura de la ceguera pone al descubierto los delitos de éstos».

Otras noticias de sucesos extraños que se producen en contacto con las aguas, presenta entremezcladas con éstas. Así menciona un lago en Etiopia, en el que los cuerpos que se bañan brillan como ungidos por aceite. En África, la fuente de Zama hace que las voces adquieran sonoridad «canoras uoces facit». En Quíos, una fuente embrutece a quienes beben de ella, mientras que cita la existencia de dos fuentes en Beocia, que proporcionan memoria y olvido respectivamente. En Cício, otra suprime el deseo sexual. En Beocia, en cambio, hay un lago que tiene el efecto contrario.

En Tesalia hay dos rios, que cambian el color de las ovejas si beben en blanco o negro respectivamente, y si abrevan de los dos se vuelven pintas.

Curiosa es la afirmación de que el lago Clitumno, en Umbría, hace nacer bueyes de gran tamaño, ya que, como indican Oroz Marcos (Op. cit., pág. 142, n. ${ }^{\circ} 30$ ), Isidoro se basa en Virgilio, Georg. 2, 146, y no ha leído bien el texto "et maxima taurus uictima», que se refiere a que los toros eran la victima más apreciada para los sacrificios, por ser blancos.

Con las lagunas de Reatina se endurecen las pezuñas de los jumentos.

En la fuente de Siloé, al pie del monte Sión, el agua surge en determinadas horas, no continuamente. En Epiro hay una fuente que apaga las antorchas encendidas y enciende las apagadas, etc.

Además de los citados, en el capítulo antes referido vuelve a incidir en el carácter curativo de las aguas al hablar del lago Tiberiades en Judea (XIII 19, 5):

"Lacus Tiberiadis ab oppido Tiberiade uocatus, quod quondam Herodes in honorem Tiberii Caesaris condidit. Est autem in ludeae omnibus lacis salubrior, et ad sanitatem corporum quemadmodum efficacior".

Esta idea, junto con la de ser uno de los elementos básicos que componen el mundo, se hereda y se recoge desde la antigüedad y está presente también a cada paso en Isidoro. Así en XIV 1, 3, al hablar de la tierra comenta:

«Alii aquam dicunt genetalem in terris moueri, et eas simul concutere, sicut uas, ut dicit Lucretius» ${ }^{6}$.

\footnotetext{
${ }^{6}$ Cfr Lucrecio, Rer. Nat., 6, 555: Ut uas interdum non quit constare, nisi humor / destitit in dubio fluctu iactariter intus.
} 
(Cuentan otros que el agua generadora se mueve en el interior de la tierra y agita al mismo tiempo ésta, como un vaso).

Pero creemos que en él, como en los autores cristianos, esta capacidad regeneradora y purificadora del agua se contempla desde una perspectiva también cristiana, cual es la capacidad purificadora y sanadora del alma a través del bautismo. Y en esta unión puede estar la clave de la continuidad y la simbiosis cultural de elementos heredados de la cultura pagana y cristiana.

\section{AGUAS TERMALES: CONSTRUCIONES. ASPECTOS RELIGIOSOS}

Arqueológicamente, termas construidas en época romana y que perduren en época visigoda, tan sólo conocemos en Hispania dos casos absolutamente claros.

El primero de ellos es el de Baños de Ledesma en la provincia de Salamanca, que surge a consecuencia de un manantial natural de aguas termales. En época romana se construyen en el lugar unas instalaciones que corresponden a una sala cubierta por una bóveda con una piscina central. En época visigoda y medieval el lugar siguió siendo conocido pues se le denominó Balneos ${ }^{7}$.

Existe una cierta similitud constructiva que permite pensar en la contemporaneidad de ambas estructuras ${ }^{8}$. Siempre se había admitido que esta fuente era de aguas medicinales, pero esto ha sido desmentido ${ }^{9}$, a pesar de que existe un texto que alude a la curación de una litiasis renal que sufría Recesvinto gracias a estas aguas. Según Lázaro de Castro ${ }^{10}$, ya celtas y romanos rendian culto a la fuente, no por su carácter medi-

\footnotetext{
7 Mora, Gloria, «Las termas romanas en Hispania», Archivo Español de Arqueologia, 54, 1981, pág. 55. El extenso artículo de G. Mora proporciona abundante información sobre termas romanas y rastreándolo se puede llegar a obtener documentación sobre períodos más tardíos.

${ }^{8}$ No lo cree asi H. Schlunk, que afirma que se trata de diferentes períodos cronológicos. Véase ScHLUNK, Helmut y HAuSCHILD, Theodor, Die Denkmäler der frühristlichen und westgotischen Zeit, Hispania Antiqua. Maguncia 1978, pág. 106.

${ }^{9}$ Castro Garcia, L. de, «El castro de Tariego de Cerrato y la fuente medicinal de la basílica visigoda de San Juan de Baños», XIl Congreso Nacional de Arqueología, 1973. Zaragoza 1975, págs. 985-990.

${ }^{10}$ Castro Garcia, «El castro de Tariego», Op. cit., págs. 985-990.
} 
cinal, sino por su carácter de fuerza de la naturaleza. Quizá debamos leer entre líneas y permitir una asimilación de ambos conceptos. Las gentes que rendían culto a esta fuente eran los habitantes del cercano castro de Tariego de Cerrato, ocupado en época romana y muy posiblemente con perduraciones en la Antigüedad tardia, fruto de lo cual tendriamos pervivencias culturales también en época visigoda.

En relación directa con el culto a la fuente de Baños de Cerrato, tanto en épocas precedentes como visigoda, se encuentra la escasa, aunque significativa, presencia de algunos epígrafes, que, dentro del conjunto general de inscripciones relativas a fuentes, ninfas, etc., conservadas en Hispania, podemos destacar aquí por estar estrechamente relacionados con el tema y en concreto el lugar al que hacemos referencia ${ }^{11}$.

Como es sabido se publicó una inscripción por Fita en $1895^{12}$ y publicada en el CIL II 5760. Después de Fita, cuya lectura, interpretaba Numini sacrum v(olo) s(oluto), -también interpretada como v(otus) c(umplit) por autores como Sagredo ${ }^{13}$ - se corrigió la lectura ya por Dubois y últimamente se ha establecido su texto por A. Stylow y editado por J. Mangas. En él queda establecido definitivamente la dedicación a las Ninfas, al leerse:

Numphi/s (hedera) sac/rum (dos hederae)/voti (hedera) c(ompos) (hedera).

Esta lectura cambia la interpretación religiosa del texto que, como señala Mangas pasan de ser unas divinidades imprecisas de la vegetación o de los campos (Numina) a las "Ninfas», es decir divinidades veneradas en diversos balnearios ${ }^{14}$.

El mencionado autor, puntualiza también que otra inscripción publicada por Rivero, en el lapidario del MAN, procedente del mismo lugar, donde se lee en un ara la palabra NVMAD, habría que interpretarla igualmente como NVMPHIS.

\footnotetext{
11 Véase Palol, P. de; Tuset, F. y Cortés, J., “Excavaciones en la iglesia visigoda de San Juan de Baños. Palencia, 1982", Publicaciones de la Institución Tello Téllez de Meneses, 49, 1983, págs. 243-264, XXXIX láms., 9 figs., cf. pág. 263. PALoL, P. de, La basílica de San Juan de Baños. Palencia 1988, pág. 19.

${ }_{12}$ En el Boletín de la Real Academia de la Historia, 26, 1895, pág. 94.

13 Sagredo, L.-Crespo, S., "Epigrafía romana de la provincia de Palencia", PITTM, 40, 1978, pág. 57.

${ }_{14}$ Mangas, J., «Sociedad y religión del municipio Flavio de Pallantia (Palencia)", /I Congreso de Historia de Palencia, I, 1990, págs. 695-709. Véase concretamente págs. 705-706, con las referencias bibliográficas a las sucesivas ediciones e historia de la publicación del texto.
} 
Estas inscripciones señalan el indudable carácter salutífero de las aguas y su culto a las ninfas.

Con independencia del corte cronológico que supone la existencia de estas inscripciones y la construcción muy posterior de la basílica, parece que puede establecerse una continuidad en cuanto a la consideración y conocimiento del carácter o propiedades curativas de las aguas de Baños de Cerrato, aguas que, al parecer, habrian hecho sanar a Recesvinto, según hemos dicho ya, y serían el motivo por el cual éste habría ordenado la construcción de la basílica cuya dedicación es tan conocida ${ }^{15}$.

+ Praecursor D(omi)ni, martir Babtista lohannes, posside constructam in eterno munere sedem quam deuotus ego rex Reccesuinthus, amator nominis ipse tui, proprio de iure dicaui tertii post dec(e)m regni comes inclitus anno, sexcentum decies era nonagesima nobem.

\section{CONSTRUCCIONES Y EDIFICIOS}

Si retomamos el texto de Isidoro podemos ver cómo en él se encuentran referencias a termas, baños y otras construcciones relacionadas con el agua, así en XV 2, 39 y ss:

"Thermas appellatas quod caleant; Graeci enim "Cermón" calorem uocant. 40 Balneis uero nomen inditum a leuatione maeroris; nam Graeci "balaneïon" dixerunt, quod anxietatem animi tollat. Haec et gymnasia dicuntur; nam "gumnásion" Graece, Latine exercitum dicitur. 41. Apodyterium, ubi lauantium uestimenta ponuntur, ab xeundo scilicet dictum; "apodúein" enim Graece exuere dicitur. 42. Propina Graecus sermo est, quae apud nos corrupte popina dicitur. "Peïna" eim Graece famem significat, eo quod hic locus famem tollat. 43. Tabernae olim uocabantur aediculae plebeiorum paruae et simplices in uicis, axibus et tabulis clausae; unde et tabernariae quod ibi solebant consdere. Dictae autem taberae quod ex tabulis lignisque erant constructae, quae nuc et si non speciem, nomen tamen pristinum retinent».

${ }^{15}$ FITA, F., «Inscripciones visigóticas y suévicas de Dueñas, Baños de Cerrato y San Pedro de la Roca", Boletín de la Real Academia de la Historia, XII, 1902, págs. 476-511. Véase también Navascués, J. M. de, La dedicación de San Juan de Baños. Palencia 1961. Mariné, S., Inscripciones hispanas en verso. Barcelona 1952, págs. 14, 58, 95. 
(Las termas se llaman asi porque calientan y los griegos llaman al calor, thermós. A los baños se les da este nombre porque alivian la tristeza, pues los griegos lo llamaron balaneîos, porque quitan la ansiedad del espiritu. Se llaman también gimnasios porque alli los atletas se ejercitaban con el cuerpo ungido de aceite y bien friccionado; en griego se dice gymnásion y en latín ejercicio. El apodyterium es el lugar donde depositan sus vestidos los que van a lavarse. Se denomina así por la acción de desvestirse que en griego se dice apodeyn. Propina [taberna] es palabra griega que, entre nosotros, de forma corrompida se dice popina. Es un local próximo a los baños públicos en el que, después del baño, se reponen los bañistas de su hambre y su sed...).

El uso de termas romanas durante la época visigoda es muy dificil de rastrear. Así ocurre, por ejemplo, con las termas urbanas de Mérida, que son completamente desconocidas. Las estructuras halladas en la c/ General Aranda, 15, parece que deben ponerse más en relación con un lugar de culto cristiano, quizá un baptisterio, que con un espacio termal público ${ }^{16}$.

Más verídicos resultan los datos ofrecidos por el estudio de las termas de Alange (Badajoz), lugar que puede ser identificado con Aquae, donde el rey visigodo Wamba creó otra sede episcopal y donde se encuentra la consagración del obispo Cuniuldus ${ }^{17}$. En Alange mismo y toda la zona que lo circunda han aparecido restos paleocristianos y esculturas visigodas que testimonian un hábitat muy denso, al menos, en el siglo vi. En el lugar de la llamada Ermita del Cristo de los Baños, dentro de la casa de las termas, hay piezas escultóricas - al parecer visigodas - incluidas o reutilizadas en la construcción ${ }^{18}$. Tal como sugiere José María Álvarez, creemos que las termas de Alange estuvieron en plena utilización en época visigoda, continuidad que perduró en la Edad Media hasta nuestros dias ${ }^{19}$. Se trata, por tanto, de uno de los casos más claros de continuidad y pervivencia del termalismo en la Lusitania.

\footnotetext{
${ }^{16}$ Almagro, Martín, Guia de Mérida. Valencia 1983 (10, edición), pág, 85.

17 Álvarez Saenz de Buruaga, J., Panorama de la arqueología emeritense, Discursos leídos ante la Real Academia de Extremadura, 981. Badajoz 1984, pág. 27.

${ }_{18}$ VILLALÓN, M. Cruz, "Dos enclaves visigodos en la provincia de Badajoz: Almendral y Alange», ANAS, 1, 1988, pág. 209.

19 Véanse los importantes trabajos de este autor sobre todo el conjunto: Álvarez, J. M. "Las termas romanas de Alange», Habis, 3, 1972, págs. 267-290. Idem, "Alange y sus termas romanas", Revista de Estudios Extremeños, XXIX, III, 193, págs. 445-494. Agradecemos al Dr. J. M. Álvarez las informaciones que nos ha proporcionado y sus juicios acerca de Alange.
} 


\section{OTRAS CONSTRUCCIONES}

Cabe hablar, en relación con el tema que tratamos, todavía de la fuente isidoriana sobre construcción de edificios, cuando menciona los xenodochia, por lo que estos tienen la estrecha conexión con el carácter curativo, con el aspecto terapéutico que se desprende del valor del termalismo y culto a las aguas.

En relación con los xenodochia se lee en XV 3, 13:

"Cum Hierosolymam Antiochus obsideret, Hyrcanus princeps ludaeorum reserato Dauid sepulcro, tria milia auri talenta inde abxtraxit, ex quibus trecenta Antiocho dedit, ut obsidionem reliqueret; atque ut facti inuidiam demeret, fertur ex reliqua pecunia instituisse primus xenodochia, quibus aduentum susciperet pauperum et peregrinorum; unde et uocabulum sumpsit. nam ex graeco in Latinu «xenodojeïon" peregrinorum susceptio nuncupatur. Vbi autem aegrotantes de plateis colliguntur, "nosokomeïon" Graece dicitur; in quo consumpta languoribus atque inediis miserorum membra fouentur".

No podemos dejar de citar aquí, en relación con los xenodochia, cuyo origen nos propone Isidoro, la construción del xenodochium de Mérida, construido por Masona. En la Vida de los padres emeritenses se nos describe la ferviente actividad constructiva de Masona desde su sede episcopal. Así señala que «al comienzo de su episcopado fundó muchos monasterios, los enriqueció con grandes propiedades, construyó con admirable esfuerzo numerosas basílicas y allí mismo consagró muchas almas a Dios. Después edificó un hospital y lo enriqueció con un gran patrimonio, equipándolo con sirvientes y médicos; mandó que se atendieran las necesidades de los peregrinos y enfermos y dio orden de que los médicos recorriendo sin cesar los alrededores de toda la ciudad llevaran al hospital, cogiéndolo en sus brazos a cualquiera que, siervo o libre, cristiano o judío, encontraran enfermo y alli mismo, con camas acondicionadas, tendieran al enfermo en un lecho limpio, preparándole alimentos delicados y excelentes hasta que devolvieran, con la ayuda de Dios la antigua salud al enfermo en cuestión. $Y$ aunque el hospital se abastecía de los campos cultivados, con abundancia de buenos alimentos para muchos refugiados, todavía le parecía que era poco al santo varón. $Y$ añadiendo a todos estos beneficios otros mayores, ordenó a los médicos que con atenta solicitud, se preocuparan de coger, la mitad de todos los obsequios traídos del patrimonio de la iglesia por todos los actuarios eclesiásticos, para entregársela a los mismos enfermos». 
Relacionado con este xenodochium se ha interpretado tradicionalmente la inscripción que podría haber estado en la puerta del mismo, la denominada de la Domus Eulaliae:

+ HANC DOMVM IV-

RIS TVI PLACATA POSSIDE

MARTIR EVLALIA

VT COGNOSCENS INIMICVS

CONFVSVS ABSCEDAT

VT DOMVS HEC CVM HABI-

TATORIBVS TE PROPITIANTE

FLORESCANT

AMEN ${ }^{20}$.

Recientemente Pedro Mateos ha excavado en Emerita Augusta un gran edificio. Se halla situado en un solar "extramuros» de la ciudad antigua, entre el edificio circense y la basílica de Santa Eulalia. La identificación de esta construcción todavía no ha sido realizada, pero los materiales aparecidos pertenecen a los siglos VI y vII y probablemente correspondan al xenodochium del que hablan las fuentes que hemos citado ${ }^{21}$.

Dentro de los edificios sagrados, Isidoro (Etym. XV 4, 9) menciona los delubra, explicando la diferencia entre sus usos antiguos y los contemporáneos a él. La transformación de estos templos sagrados paganos en los cristianos dotados de fuentes sagradas está tomada de Tertuliano y Jerónimo, sin embargo, además de introducir un elemento mágico o simbólico como el número siete ${ }^{22}$, hace una referencia a la existencia de estas fontes in delubris, en su momento, al decir «lpsa sunt nunc aedes». El texto, interesantisimo por lo que tiene tanto de descripción del edificio, como de su fución religiosa y purificadora de las aguas de sus fuentes, dice asi:

«Delubra ueteres dicebant templa fontes habentia, quibus ante igressum diluebantur; et appellari delubra a diluendo. Ipsa sunt nunc aedes

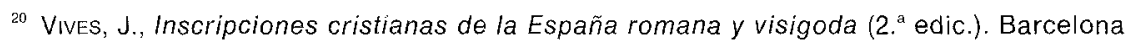
1969, n. 348. Véase también GaRviN. J. N., The Vitas Sanctorum Patrum Emeritensium. Text and translation, with an introduction and commentary. Washington 1946; que ve cierta semejanza con la oratio in introitu domus del Liber Ordinum.

${ }^{21}$ Este investigador todavia no ha publicado los resultados de la excavación, pero sabemos que está preparando su publicación y además ha pronunciado algunas conferencias sobre el tema. Desde aqui queremos agradecer a Pedro Mateos su ambilidad y las informaciones que siempre nos ha proporcionado.

${ }^{22}$ Cfr. Reta, Oroz-Casquero, Marcos, pág. 238, n. 49. Describe la fuente bautismal, tomándolo de Tertuliano y San Jerónimo, Ep. ad Rusticum. Pero resulta curiosa la designación de los tres escalones de subida, tres de bajada y un cuarto donde se detendría el bautizado.
} 
cum sacris fontibus, in quibus fideles regenerati purificantur: et bene quodam praesagio delubra sunt appellata; sunt enim ablutionem peccatorum. 10. Fons autem in delubris locus regeneratorum est, in quo septem gradus in Spiritus sancti mysterio formantur; tres in descensu et tres in ascensu; septimus uero is est qui et quartus, id est similis Filio homiis, extinguens fornacem ignis, stabilimentum pedum, fundamentum aquae, in quo plenitudo diuinitatis habitat corporaliter".

(Los antiguos daban el nombre de delubra a los templos dotados de fuentes en las que se purificaban antes de entrar en ellos. El nombre de delubra viene de diluere [purificarse con agua]. Hoy día este nombre se da a los templos provistos de fuentes sagradas en las que los fieles son regenerados y purificados. Se les denominó delubra con un buen presagio pues sirven para la ablución de los pecados. En los delubra, la fuente es el lugar de los regenerados. En ella se forman siete gradas en el misterio del Espíritu Santo: tres de bajada y tres de subida; el séptimo grado - que es el cuarto escalón- equivale al hijo del hombre, el cual extingue el horno del fuego, sirve de apoyo estable a los pies y da fundamento al agua; en él habita corporalmente la plenitud de la divinidad).

A continuación de estos delubra, hace Isidoro una descripción de las basílicas, señalando que en principio eran regnum habitacula, pero en ese momento se designa con tal nombre a los templos, ya que en ellos se rinde culto y ofrecen sacrificios a Dios, rey de todos.

La arqueología nos muestra algunos casos contrarios a la continuidad, reutilizando los ámbitos termales como lugares de culto cristianos. Un claro ejemplo es el proporcionado por Ampurias (Gerona). En la llamada neápolis de la ciudad y junto a la zona portuaria, se construyó en el siglo I d. C. un apodytherium termal ${ }^{23}$, que fue reutilizado más tarde como basílica cristiana ${ }^{24}$, funcionando en época visigoda y como campo funerario hasta el siglo XI.

Otro caso similar donde no se respeta el edificio anterior, o se reutiliza con otros fines, es el de las termas orientales de Segóbriga (Cuenca), que se encuentran actualmente muy destruidas pues sobre ellas se instaló una necrópolis hispano-visigoda ${ }^{25}$.

\footnotetext{
${ }^{23}$ Ripoll, Eduardo, Ampurias, descripción de las ruinas y Museo Monográfico. Barcelona 1969 (6. ${ }^{a}$ edición), págs. 28-29.

${ }^{24}$ PALOL, P. de, Arqueologia cristiana de la España romana, CSIC. Madrid-Valladolid 1967, págs. 32-36.

${ }^{25}$ Almagro Basch, Martín, «La necrópolis hispano-visigoda de Segóbriga, Saelices (Cuenca)", Excavaciones arqueológicas en España, 84. Madrid 1975.
} 
Acerca de las lápidas de las ninfas de San Juan de Baños no volveremos a insistir, puesto que el lugar determinado de su hallazgo no parece claro e, incluso, es posible que no formasen parte de las fundaciones de dicha iglesia.

\section{PERVIVENCIA DEL CULTO A LAS AGUAS. ASPECTOS RELIGIOSOS $Y$ MÁGICOS EN LOS TEXTOS Y EN LA ARQUEOLOGIA}

Como señala José María Blázquez ${ }^{26}$, el culto a las aguas muestra una continuidad impresionante desde el Neolítico hasta hoy, y no ha llegado a ser abolido por ninguna religión, tendiendo incluso a ser tolerado en diversos momentos, dado su enraizamiento popular. Esto explica la pervivencia de antiguas fuentes que, existiendo antes del cristianismo, se transformaron en lugares de culto cristiano, bajo la advocación de la Virgen o de santos, realizándose con ello un sincretismo entre las creencias antiguas paganas y la religión cristiana, a la vez que, en muchos casos, una unión entre el culto a las aguas y la finalidad práctica de la devoción, en tanto que lugares - fuentes, piscinas, etc.- con propiedades curativas ${ }^{27}$.

Tanto las fuentes epigráficas como literarias suministran información de la extensión en la Peninsula Ibérica del culto a las aguas, a la vez que de otras creencias y supersticiones de carácter popular, ligadas a la magia y la adivinación. El autor antes citado recoge los testimonios escritos relativos a este tema, destacando, entre las fuentes literarias griegas y romanas, especialmente a Estrabón, Plinio, Livio, Suetonio, Floro, Silio Itálico.

Isidoro de Sevilla vuelve a recoger noticias e información sobre las diversas prácticas mágicas de la Antigüedad, así como de las diferentes herejías. No hay unas referencias expresas a la época coetánea a él y su

${ }^{26}$ Blázquez, J. M., «El culto a las aguas en la Peninsula lbérica», Imagen y mito. Estudio sobre religiones mediterráneas e ibéricas. Madrid 1977, págs. 307-331. Cfr. pág. 327.

${ }^{27}$ Véase para esto precisamente la obra antes citada de BLAZQUEZ, J. M., Op. cit., págs. 328-330, donde se mencionan los casos del monumento de Santa Eulalia de Bóveda en Lugo y la pátera consagrada a Salus Umeritana, como ejemplos característicos del culto a las aguas que se transforma y adapta en época cristiana, pero perviviendo en ellos el carácter cultual de las aguas. 
texto tiene el valor aquí de carácter erudito y enciclopédico, que se basa en las fuentes anteriores y en los conocimientos del momento ${ }^{28}$.

Dentro de los aspectos religiosos podemos destacar la referencia puntual que da Isidoro a ciertas herejias relacionadas con el agua. Así en VIII 4,11 habla de los hemerobaptistas, que lavan diariamente sus cuerpos, casas y vestidos, dentro del grupo de herejías de los judíos.

Entre las herejías de los cristianos refiere la de los acuarios, en VIII 5,23 , que ofrecen sólo agua en la cáliz de los sacramentos, siguiendo a Agustín en su epístola De haeresibus, dirigida a Quodvulteo.

Isidoro habla de los magos, recogiendo tradiciones antiguas, comenzando por Zoroastro y siguiendo por una serie de tipos de magia vigentes en otras épocas, tanto de la cultura hebraica como greco-latina. Sin embargo, desde una perspectiva histórica, donde no parece hacer referencia a situaciones coetáneas. Así dice en VIII 9, 3 «Y así esta vanidad de las artes mágicas, emanada de los ángeles perversos, estuvo vigente durante muchos siglos en todo el orbe de la tierra».

Dentro del grupo de los magos menciona a los hidromantes. Define la hidromancia con la evocación, mediante la observación del agua, de las sombras de los dernonios, ver sus imágenes o espectros, escuchar de ellos alguna información y, empleando sangre, buscar información en los infernos ${ }^{29}$. Tal tipo de magia o adivinación se dice introducida por los persas. Se hace eco Isidoro de la clasificación de las adivinaciones de Varrón, según se usen los cuatro elementos básicos de la cosmología antigua: tierra, agua, aire y fuego. «De acuerdo con esto se denominan, respectivamente, geomancia, hidromancia, aeromancia, piromancia».

Como transmisor de la cultura clásica, recoge la tradición relativa a los dioses paganos. Entre ellos dedica un párrafo a las ninfas, en VIII 11, 96, como diosas de las aguas, señalando que su nombre deriva de «nube», ya que las nubes provienen del agua denominándolas «quasi numina lympharum» y señalando que con razón se las llama también Musas, «nam aquae motus musicen efficit». Dentro de las ninfas recoge la clasificación de las de los montes, Oréades, bosques, Dríades, fuentes, Hamadríades, campos, Náyades, y mares, Nereidas.

${ }^{28}$ Sobre el valor del texto de Isidoro, concretamente referido a la descripción de ciencias ocultas - magos, nigromantes, hidromantes, adivinos, astrólogos, etc.--, descritos especialmente en Etym. VIII 9, Cfr. Menéndez Pelayo, M., Historia de los heterodoxos españoles. Santander 1948 (reed. Madrid 1986), I, págs. 305-309. También para todo lo relativo a artes mágicas y adivinación en época visigoda.

${ }_{29}$ Cfr. Agustín, De ciu. Dei 7,35 , dedicado a la hidromancia. 
Evidentemente estas referencias relativas al culto a las aguas y divinidades y creencias diversas relacionadas con ellas se inscriben dentro del estudio que Isidoro realiza sobre las sectas religiosas en su libro VIII dedicado, en general, a la Iglesia y las sectas, De Ecclesia et sectis, con un valor, como hemos dicho de erudición y no testimonial de la pervivencia de estos cultos a las aguas. Sin embargo, otras fuentes de época visigoda pueden apoyar la opinión de que algunas de estas prácticas tenian vigencia en la sociedad del momento y no serian meras referencias a otras épocas o lugares. Para ello debemos acudir a otros testimonios.

Hasta ahora hemos mantenido como hilo conductor de las fuentes de época visigoda los textos de las Etimologias, en cuanto que transmisores de la herencia cultural greco-latina y de la vigencia de las generalidades que sobre el valor y la existencia de aguas diversas, termales, curativas, cuasi mágicas, o de edificios y construcciones relacionados con ellas comenta el hispalense.

Es el momento, pues, de pasar a otra de las fuentes conocidas y siempre citada cuando se quiere hablar de la pervivencia del culto a las aguas en la vida de Hispania de estas épocas. Nos referimos, claro está, a Martín Dumiense, obispo de Braga, que es, sin duda alguna, una de las principales fuentes de información literaria que conservamos sobre la pervivencia de creencias de carácter mágico o supersticioso entre la sociedad rural de época visigoda. Su libro De correctione rusticorum es cita obligada para este tema.

Ya desde el inicio de su exposición, una vez que cuenta el origen de la caída de los ángeles, la pérdida del paraiso y la llegada del diluvio, hace referencia en el punto 6 precisamente a cómo después de la recuperación del género humano tras el diluvio, gracias a los hijos de Noé y sus mujeres que lo repoblaron, los hombres comenzaron a idolatrar a otras criaturas, así «Alii adorabant solem, alii lunam uel stellas, alii ignem, alii aquam profundam uel fontes aquarum, credentes haec homnia non a deo esse facta ad usus hominum, sed ipsa ex se orta deos esse».

Interpretando los dioses de la mitologia greco-latina como diablos o demonios depravados que se muestran a los hombres bajo diversas formas y en sitios distintos, señala que mandaron a los hombres que les adorasen, ofrecieran sacrificios, les edificaran templos, imágenes, etc. $Y$ añade que mandan en los ríos, fuentes y bosques, y así se invoca a Neptuno en el mar, a los Lamias en los ríos, a las ninfas en las fuentes, a las Dianas en los bosques.

Las referencias del Dumiense deben entenderse como pervivencias de supercherias de su época, al menos en una gran mayoría. Tal es el motivo de esta obrita. Asi se justifica que diga en 12: 
Non intellegitis aperte quia metiuntur uobis daemones in istisi observationibus uestris quae uane tenetis, et in auguriis quae adtenditis frequentius uos inludunt?

(¿No comprendeis que los demonios se burlan abiertamente de vosotros en estos cultos que vanamente conserváis y que se burlan repetidamente en los augurios que escucháis?).

Los capítulos 13 a 16 son reveladores, tanto desde el punto de vista de la pervivencia de ciertas supersticiones en general, y en particular relativas al culto de las aguas, como, por contraposición el valor del bautismo como medio de conversión y salvación. Por otra parte, indicador de la costumbre introducida a través del culto a los santos de la adopción de nombres de santos para nombres de personas a través del bautismo, en las fuentes bautismales ${ }^{30}$.

Cristo ordenó a sus apóstoles que anunciaran la resurrección del hijo de Dios y que les bautizaran y que «docerent illos qui baptizati fuissent recedere a malis operibus, id est ab idolis, ad homicidio, a furto, a fornicatione, et quod sibi nollent fierii aliis non facerent». En 14 menciona la salvación por el bautismo y la condena de quienes no han sido bautizados, o siéndolo, han vuelto a pecar.

En 15 señala:

15. Vos ergo, fideles, qui in nomine patris et filii et spiritus sancti ad Christum baptismum accessistis, considerate quale in ipso baptismo pactum cum deo fecistis. Nam cum singuli nomen uestrum dedistis ad fontes, uerbi gratia, aut Petrus aut lohannes aut quodlibet nomen, sacerdote interrogati fuistis: «Quomodo diceris?». Respondisti aut tu, si iam poteras respondere, aut certe qui pro fidem te fidem feci, qui te de fonte suscepit, et dixit, uerbi gratia, "lohannes dicitur».

A continuación sigue el pasaje tantas veces citado sobre la pervivencia de ritos paganos y supersticiones, dado que Martín los enumera como hechos que se dan entre los campesinos en esos momentos. Entre éstos se relacionan con las aguas, los de encender velas junto a las fuentes, también junto a las piedras, árboles y encrucijadas. Además la de poner pan en las fuentes ${ }^{31}$.

30 Cfr. Garcia Rodriguez, C., El culto de los santos en la España romana y visigoda, CSIC. Madrid 1966, pág. 373.

31 Sobre la relación de estas prácticas y, en general, del carácter de culto popular y su pervivencia en la zona de Galicia, cfr. la edición de la obra de R. Jove, y los comentarios en nota 15 y 19 especialmente. 
Nam ad petras et ad arbores et ad fontes et per trivia cereolos incendere, quid est aliud nisi cultura diaboli?... Vulcania et Kalendas observare, mensas ornare, et lauros ponere, et pedem observare, et fundere in foco super truncum frugem et uinum, et panem in fontem mittere, quid est nisi cultura diaboli?...

(Pues encender velas junto a las piedras, árboles, fuentes, encrucijadas ¿qué otra cosa es sino culto al diablo? Celebrar las Vulcanales y las Calendas, adornar mesas y poner ramas de laurel, prestar atención al pie que se usa, derramar grano y vino en el fuego sobre un tronco y poner pan en las fuentes qué otra cosa es, sino culto al diablo?).

Blázquez señala con razón que «el culto a las aguas y a las fuentes estuvo muy extendido en Hispania, como se deduce de la frecuencia con que su culto es aludido en la obra de San Martín Dumiense y en los concilios visigodos» ${ }^{32}$.

En efecto, como hemos indicado, estas menciones de Martín deben entenderse como llamadas de atención contra quienes practican cierto tipo de magias, entre las cuales, permanece viva la del culto a las aguas, en sus diversas facetas. Del mismo modo deben entenderse las prohibiciones de algunos concilios visigodos.

Información complementaria sobre supersticiones vigentes en época visigoda, nos la dan algunos cánones conciliares. Precisamente el Concilio II de Braga, del 572, presidido por Martín Dumiense. Los cánones 71 a 75 se dedican a las supersticiones de los cristianos ${ }^{33}$. En el 71 hay una referencia a purificaciones, lustrationes, de los paganos, así como introducir adivinos en casa, etc.:

Si quis paganorum consuetudinem sequens diuinos et sortilegios in domo sua introduxerit, quasi ut malum foras mittant aut maleficia inueniant uel lustrationes paganorum faciant, quinque annis poenitentiarum agant.

El Concilio IV de Toledo insiste también en su canon 29 sobre la prohibición hecha a los clérigos de consultar magos o adivinos, obligándoseles, en caso de que lo hagan, a permanecer encerrados en un monasterio, dedicados a realizar una penitencia perpetua.

${ }^{32}$ BLÁzQuez J. M., «El sincretismo en la Hispania romana entre las religiones indigenas, griega, romana, fenicia y mistérica», en La religión romana en Hispania. Madrid 1981, pág. 200 .

${ }^{33}$ El 59, por su parte prohibe a los clérigos practicar encantamientos y el 69 a los cristianos llevar alimento a las tumbas de los difuntos y ofrecer sacrificios a Dios en honor de los muertos. 
En el Concilio XII de Toledo, el canon 11 trata el tema de los adoradores de idolos y comienza señalando que son preceptos de Dios que señala lo siguiente:

"Non facies sculptile neque omnem similitudinem quae est in caelo desuper et quae in terra deorsum, neque horum quae sunt in aquis sub terra: non adorabis ea neque coles".

Se promulga en este canon una sentencia con la que se pretende avisar a los adoradores de los idolos, a los que veneran las piedras, a los que encienden antorchas y adoran las fuentes y los árboles, que reconozcan cómo se condenan espontáneamente a muerte aquellos que hacen sacrificios al diablo:

«... sed cultores idolorum, ueneratores lapidum, accensores facularum et excolentes [sacra] fontium uel arborum admonemus ut agnoscant quod ipsi se spontaneae morti subiciunt qui diabolo sacrificari uidentur, ,..».

Se exponen las penas después a las que serán castigados, se contempla como generalidad a siervos, a los cuales se azotará y después se entregará encadenados a sus señores y si éstos no los aceptan serán conducidos ante el rey, que dispondrá su donación. A continuación se dispone que si los que incurren en estas idolatrías fueran libres se les castigará con la excomunión y el destierro.

En términos similares se expresa el canon 2 del Concilio XVI de Toledo ${ }^{34}$.

Estos cánomes junto con el texto del Dumiense ponen de manifiesto que, paralelamente, al mundo cristiano seguian existiendo creencias arraigadas en la sociedad y que tuvieron un desarrollo popular tremendo. Una continuidad, por tanto, de creencias de origen romano, e indígena en muchos casos, que hereda la sociedad hispano visigoda y que, como en otros ámbitos, muestra esa pervivencia especialmente en ámbitos rurales, como parece deducirse del De correctione rusticorum de Martín de Braga.

${ }^{34}$ Destacamos estos textos, dentro del conjunto de alusiones de los cánones conciliares a herejías y prácticas supersticiosas y mágicas, por hacerse en ellos mención explícita al culto a las aguas. Su mención puede consultarse en BLAZQUEZ, El culto a las aguas, op. cit., pág. 325 y Menéndez Pelayo, Historia de los heterodoxos españoles, op. cit., págs. 307-308. En este mismo autor se hace referencia a otras fuentes que tratan diversos tipos de magos y magias: Lex Visig. VI 2, 1, 3, 4, o Paciano. 
El panorama es diverso cuando analizamos la pervivencia en el ámbito de la arqueologia, especialmente en ámbitos rurales y, en concreto, a la pervivencia de termas en las uillae.

En cuanto a esta posible continuidad de la utilización de las termas de las uillae, existen varios ejemplos, sobre todo lusitanos, que permiten afirmar esta pervivencia. En primer lugar señalaremos la uilla de la Nava (Badajoz), puesto que se trata de un yacimiento unitario que gira en torno a un establecimiento termal minero-medicinal. Su fundación se sitúa hacia finales del siglo 1 d. C., precisándose una segunda fase a finales del siglo $\|$ y principios del siglo $\mathrm{II}$, momento en que se remodela toda la planimetría del espacio termal y que se adecúan las instalaciones. Los investigadores que se han ocupado del conjunto creen, aunque no lo afirman, que las instalaciones termales debieron utilizarse al menos hasta época visigoda e incluso posteriormente ${ }^{35}$.

Otro de los yacimientos de la Lusitania que nos interesa recalcar es el de la uilla de Torre Aguilar (Badajoz). En esta uilla se ha hallado una zona residencial, unas termas, un mausoleo y un baptisterio, por tanto, nos encontramos con estructuras que entran de lleno en la Antigüedad tardía.

Ya en el siglo xvIII, B. Moreno de Vargas, señaló la existencia de unos restos que él creyó de época visigoda ${ }^{36}$, pero que posteriormente han sido confirmados como un establecimiento termal ${ }^{37}$. La primera época de la cillla ha sido fechada en el siglo I d. C. y la última fase correspondería ya al siglo $\vee d$. C. ${ }^{38}$. Los investigadores que se han ocupado de su estudio creen que podría tratarse de la uilla de Ponciano, a la que se haria alusión en el himno de Peristephanon de Prudencio en honor al martirio de Santa Eulalia (himno III vv. 36-66):

Sed pia cura parentis agit, uirgo animosa domi ut lateat abdita rure et ab urbe procul, ne fera sanguinis in pretium

${ }^{35}$ Calero Carretero, José Ángel, «El complejo termal romano del "la Nava" (Cabeza del Buey, Badajoz). Cuatro campañas de excavaciones (1979-1983)", Extremadura Arqueológica, I. Salamanca 1988, págs. 155-166, 3 figs.

${ }^{36}$ Moreno de Vargas, Bernabé, Historia de la ciudad de Mérida, 1633 (reedición 1989), pág. 459.

37 Rodriguez Martin, Francisco Germán, «La villa romana de la Dehesa de Torre Aguilar en Barbaño-Montijo (Badajoz)", Extremadura Arqueológica, I. Salamanca 1988, págs. 201219.

${ }^{38}$ Ronriguez Martin, «La villa romana de la Dehesa de Torre Aguilar», op. cit., pág. 217. 
Pervivencias del termalismo y el culto a las aguas en época ...

mortis amore puella ruat.

Illa perosa quietis opem

degeneri tolerare mora

noctes fores sine teste mouet

saeptaque claustra fugax aperit,

inde per inuia carpit iter.

Illa gradu cita peruigili

milia multa prius peragit,

quam plaga pandat eoa polum

mane superba tribunal adit,

fascibus adstat et in mediis,... ${ }^{39}$.

Otra de las uillae lusitanas conocida por la literatura arqueológica desde antiguo es la de la Dehesa de la Cocosa (Badajoz) donde creemos que existen pervivencias de termalismo puesto que hay edificaciones relativamente tardías en uso. En época cristiana y visigoda se construyó un templo con doble ábside en ambos extremos de un eje mayor -probablemente esta atribución sea errónea-, también una capilla funeraria y un martyrium. Si realmente el edificio de la Cocosa es una basílica, ésta se construyó junto a las termas, lo cual no indica en principio nada, pero sí permite imaginar que todo el conjunto de la uilla se utilizó hasta una fecha tardía ${ }^{40}$.

De Portugal, debemos recalcar la gran uilla de Heredade de Algramça (Pisôes, Beja), donde fueron halladas unas termas independientes situadas al Noroeste. En las termas, las piscinas estaban revestidas con mosaicos de temas marinos. La cronología del conjunto ha sido establecida entre el siglo । d. C. y el siglo VIII d. C., puesto que se han encontrado restos escultóricos caracteristicos de talleres visigodos ${ }^{4 i}$. Ello permite establecer la hipótesis del funcionamiento termal durante este periodo tardío.

${ }^{39}$ El cuidado solícito de su padre contiene a la animosa doncella; la lleva al campo, lejos de la ciudad, para que la intrépida muchacha no compre a precio de sangre su amor a la muerte.

No pudiendo ella aguantar el descanso ni contenerse en la demora indigna, de noche, cuando nadie la ve, hace girar las puertas y fugitiva abre los portones de la cerca y emprende su camino campo através...

Ella, rápida en su diligente marcha, anduvo muchas millas antes que la región del oriente abriera el cielo, e intrépida, se presenta aquella mañana misma al juez y a los magistrados de la ciudad.

Traducción de GuILÉN, José, Obras completas de Aurelio Prudencio. Madrid, BAC, 1950, 527-529.

40 Palol, Arqueología cristiana de la España romana, op. cit., págs. 136-144.

41 Alarcao, Jorge de, Portugal romano, 1983, págs. 119-120. 
En el centro de la Península, en Santa Cruz (Baños de Valdearados, Burgos) fue excavada una uilla con un conjunto termal. El asentamiento empieza a finales del siglo I o principios del siglo II d. C. y perdura hasta la época medieval. El auge de la instalación, según los materiales, se sitúa en los siglos IV y $v$. Por ello suponemos que el edificio termal estaría en uso ${ }^{42}$.

Por último, dentro de las características de continuidad y pervivencia termal por lo que a las uillae respecta, debemos señalar la monumental y suntuosa uilla de Els Munts (Altafulla, Tarragona). El complejo termal refleja unas complejas características constructivas, que como decíamos, tienden a la monumentalidad. Entre los hallazgos que deben ser mencionados, están las esculturas del siglo ॥ d. C. de Eros, Hyrgia, Antinoo y Esculapio; los mosaicos del siglo IV corresponden a algunas estructuras de la misma época. La uilla estuvo ocupada desde el siglo $1 \mathrm{~d}$. C. hasta el siglo $\vee$ d. C. y es muy posible que las termas estuviesen en plena utilización durante la Antigüedad tardia ${ }^{43}$. Por otra parte el hallazgo de un broche de cinturón liriforme vendría a confirmar su hábitat incluso en época hispano-visigoda, es decir, a todo lo largo del siglo vII.

A modo de conclusión, sobre las uillae, creemos que muchas de ellas debieron estar abandonadas en los siglos $\mathrm{V}$ o $\mathrm{v}$, pero a la vez estarían semi-visibles e incluso semi-habitables en época visigoda e hispano-visigoda. Esto creemos que no obliga, pero sí permite, la utilización de termas y de las zonas con aguas salutíferas en periodos relativamente avanzados. Lo que si parece seguro es que no implica un culto a las aguas, a pesar de que probablemente era un culto bastante difundido.

Arqueológicamente se puede, por tanto, sugerir una continuidad y una pervivencia del termalismo que debe ser revisada y delimitada en cada caso, sin que se trate de una constante clara y evidente en todas las zonas y yacimientos.

\section{APÉNDICE: DE LAS AGUAS CURATIVAS A LA PRÁCTICA MÉDICA}

De manera complementaria y casi como propuesta de tema paralelo pensamos que cabe hacer mención, siquiera sea de forma muy puntual,

\footnotetext{
${ }^{42}$ Mora, «Las termas romanas en Hispania», op. cit., pág. 59.

${ }^{43}$ Berges, P. M., "Informe sobre Els Munts", Boletín Arqueológico, LXIX-LXX, 1969-70, págs. 140-150, 16 láms.
} 
Pervivencias del termalismo y el culto a las aguas en época ...

a las referencias a la práctica de la medicina en la Hispania visigocia, por lo que de común tiene con el carácter curativo y reparador con las aguas, en la significación de éstas como elemento de propiedades terapéuticas y curativas, que de forma práctica en la vida cotidiana pudo hacer pervivir el culto a las mismas en ámbitos populares, asi como la adaptación de la cristianización del culto en el que la función de las aguas medicinales $y$ de beneficios y efectos terapéuticos y curativos tuvo probablemente mucho que ver.

Desde Eurico a Egica las leyes hablan de la existencia de médicos. La medicina en época tardía y visigoda es heredera del mundo greco-romano. Hay un declive y una evolución a partir de Galeno que antes de los nuevos desarrollos de la medicina en el mundo medieval, bizantino o islámico, parece ser tan sólo una continuación de los conocimientos adquiridos, el desarrollo o ejercicio de una profesión que, como tal, no se interpone $u$ obstaculiza a la práctica religiosa, al pensamiento cristiano. Sin embargo la práctica médica está estrechamente relacionada con la religión cristiana e imbuida de sus doctrinas.

La medicina, los conocimientos médicos heredados, se convertirán a partir del siglo $v$ en parte de la ciencia que se deposita, como las llamadas artes liberales, triuium y quadriuium, en los monasterios. Se difundirá y propagará dentro del marco del enciclopedismo y de la transmisión de la cultura. J. R. Zaragoza ${ }^{44}$ señala que puede hablarse para este período de «medicina monacal», en el sentido descrito.

En época posterior al establecimiento de los visigodos en Hispania, hay algunos aspectos de interés que pueden destacarse con respecto al conocimiento de la medicina.

En Italia, además de las consideraciones de Boecio (480-524) en su Consolación de la filosofía, sobre las enfermedades del alma y la traducción de Aristóteles, destaca la epístola del médico griego Antimo a Teuderico, donde se revelan conocimientos sobre costumbres dietéticas, alimentos, etc. A su lado la Regula Benedicti muestra diversas preocupaciones sobre el tratamiento de los enfermos y cuidados que se le deben prestar. Casiodoro, por su parte, en las Instituciones, hace mención de prácticas terapéuticas a base de plantas medicinales, señalando la necesidad de leer a los grandes escritores de medicina, Dioscórides, Hipócrates, Galeno, Celio Aureliano... Después de la invasión de los longo-

44 Zaragoza, J. R., "Restos de la medicina clásica en el occidente medieval europeo», P. Lain Entralgo (ed.), Historia universal de la medicina. Barcelona 1972 (reimpr. 1981), pág. 169. 
bardos continúa la preocupación por el conocimiento de la medicina. El Codex Lombardus, enumera una serie de médicos de la época y el Commentarium medicinale de Benedito Crispo, enumera en hexámetros una serie de enfermedades diversas.

En Hispania, la fuente más sistemática sobre el conocimiento de la medicina es Isidoro de Sevilla, quien le dedica el libro IV entero, tanto al concepto, tipos de enfermedades, remedios y medicinas, clases de libros de medicina, instrumental, ungüentos, etc.

El libro aparece tras los tres primeros dedicados a las artes liberales y revela el mismo tipo de carácter de recopilación enciclopédica del saber de su tiempo. Pero es interesante que en el último capítulo del mismo haga una justificación de por qué la medicina no se incluye entre estas artes liberales. Su justificación no puede ser más contundente, mientras que las artes liberales revelan conocimientos particulares, la medicina abarca todas. Justifica cómo el médico debe conocer todas y cada una de ellas.

Por otra parte a lo largo de la obra hace algunas referencias al conocimiento de la anatomía humana, hace hincapié en las propiedades curativas y terapéuticas de plantas, minerales, etc.

Puede decirse que las Etimologias son un excelente compendio en relación con el conocimiento médico y revelan el estado del mismo en la época del obispo hispalense.

Por otra parte, son diversas las fuentes, desde las leyes visigodas, hasta la obra anónima de las Vitas Patrum Emeritensium, que nos hablan de la situación de la medicina, las prácticas que se llevan a cabo, más frecuentes, incluso la legislación sobre el oficio de los médicos, sus honorarios, su formación, basada en la práctica diaria.

Parece que la medicina era ejercida por seglares y también por clérigos. Estos, adquiridos sus conocimientos a través de los monasterios podian ponerlos en práctica, sumando a su aptitud profesional, la caridad cristiana y altruista de atención a los enfermos.

El texto de las Vidas de los padres de Mérida es en esto elocuente. Se ha hecho notar en muchas ocasiones la operación llevada a cabo por Paulo, obispo de Mérida, de origen griego y médico de profesión, a una mujer que tenía en su seno un feto muerto y a la que todos los remedios de los médicos de la ciudad no habían conseguido sanar.

Paulo, como obispo, pone reparos a atender las súplicas del marido de la enferma, aludiendo que no le está permitido ejercer la cirujía, estando sus manos consagradas a Dios. El texto parece revelar, no una pro- 
hibición a los clérigos de la medicina, sino, más bien, de la práctica quirúrgica:

«Mihi quod hortaris facere non licet quia, est indignus, sacerdos Domini sum et sacrificium manibus meis offero Domino et ideo non possum quod dicis implere ne postmodum pollutas sacris altaribus manus inferam et divinae pietatis mox furorem incurram». Et adiecit: «lbimus, inquit, in nomine Domini; uisitamus eam et damus medicos ecclesiae qui illi adhibeant medicinam et, inquatum scimus, ostendimus qualiter cura faciant. Nos tamen facere manu propria non possumus".

Finalmente Paulo accedió ante las súplicas de sus hermanos y la promesa de que no dirian nada de su intervención.

A juzgar por el texto de las Vitas parece que existía un número considerable de médicos, sin que podamos extrapolar de él una población excesiva, pero, sin duda el texto es elocuente. Tal vez, incluso, se podria deducir del origen griego de Fidel, la penetración de conocimientos médicos desde el mundo oriental - de Bizancio-.

En relación con esto conocemos la inscripción sepulcral de un médico de Mérida (ICERV 288), datable, según Hübner IHC 526, en el siglo VI.

[Reccare]dus, medicus, debito

[func]tus hoc in sepulcro quiscit

[se]curus. uixisse fertur fere

[ann. uigin]ti $n[$ ouem]

\section{CONCLUSIÓN}

Desde el punto de vista arqueológico y del de las fuentes escritas, creemos que pueden rastrearse elementos suficientes de pervivencia del culto a las aguas y del termalismo en época visigoda. Es cierto que nos movemos en estrechos márgenes, pero cuya presencia resulta bastante clara, aunque tengamos que separar, como hemos indicado, lo que de tradición literaria y erudita nos proporcionan las fuentes, como hemos visto especialmente a través de Isidoro de Sevilla - y que, por tanto, no permiten hablar de pervivencia real, sino sólo de transmisión de la cultura heredada-, de lo que son testimonios de la continuidad viva del culto a las aguas y prácticas mágicas con ellas relacionadas, como nos muestran los texios de Martin de Braga o los cánones conciliares y que 
se complementan y encuentran su justificación en los testimonios que ofrece la arqueología.

No obstante, dentro de esta pervivencia y continuidad real en época visigoda cabe hablar de dos aspectos bien distintos: uno la herencia de la cultura pagana a través del culto a las aguas, fuentes, etc., que muy someramente se nos describe en los textos en cuanto a su ritual concreto, y otro la adaptación de este culto al cristianismo a través, como hemos señalado, del carácter práctico o utilitario de ver en estas aguas elementos curativos, de ahí que en esta época - recuérdese la inscripción de San Juan de Baños, dedicada por Recesvinto; si es cierta la afirmación de que sería en agradecimiento por su curación ert las aguas de la zona- y posteriormente hasta nuestros dias haya quedado como elemento de creencia popular, pero dentro del cristianismo, la existencia de fuentes curativas, cuando no milagrosas, junto a aquellas de carácter medicinal, por sus especiales características y propiedades.

En esta adopción del cristianismo hay, como fondo general y básico a nuestro juicio, una idea subyacente, a la que ya nos hemos referido, que podria poner de manifiesto, y ser una muestra más de ello a la vez, la simbiosis cultural entre cristianismo y paganismo en este tema concreto, cual seria la concepción del agua - esto en cualquier cultura- de un elemento regenerador de vida, purificador, utilizado en la cultura pagana como tal elemento purificador antes de entrar en los templos (recuérdese el texto de Isidoro, Etym., XV 4, 9 sobre los delubra) y utilizado en el cristianismo como elemento purificador del alma, a través del bautismo (véase también la inclusión que hace Isidoro en Etym., XIII 12, 4 -primer texto que citamos- de que las aguas "abluun peccata", limpian los pecados, junto a las múltiples propiedades de ser la causa de todo cuanto nace).

Sería ya muy largo y objeto de un estudio particular sobre el tema, analizar la relación directa o el influjo que desde la cultura occidental - grecolatina - puede haber tenido el culto a las aguas y la significación de ésas como elemento purificador sobre el uso del cristianismo, heredero de la religión judaica.

De forma paralela, esta simbiosis cultural tiene su reflejo también, como hemos señalado, en la práctica de la medicina, en la que a los conocimientos heredados del mundo pagano se añade la concepción cristiana del pecador como hombre enfermo que debe ser curado por los miembros de la iglesia y, en sentido contrario, la relación entre médicos y pacientes que se ve imbuida, al menos teóricamente, de una relación 
Pervivencias del termalismo y el culto a las aguas en época ...

cristiana piadosa, como nos recuerdan las alusiones de las Vidas de los padres de Mérida ${ }^{45}$.

RESUMEN

Este trabajo se plantea como un estado de la cuestión en el que se presentan una serie de hipótesis. Por lo que respecta a la búsqueda de elementos de pervivencia y continuidad en la Hispania visigoda, el punto de partida se encuentra en las Etimologías de Isidoro de Sevilla, aunque aquí se trata más bien de una transmisión de cultura heredada, y por tanto tiene un valor de erudición más que testimonial de existencia de un culto a las aguas. Otra fuente importante la constituye la obra De correctione rusticorum, de Martín Dumiense, Obispo de Braga, referida a la pervivencia de creencias de carácter mágico o supersticioso, además de algunos cánones conciliares. Se mencionan algunas termas en uso en época visigoda, completándose el estudio con un apartado dedicado a otras construcciones, además de un apéndice referido a las aguas curativas y a la práctica médica.

\section{ABSTRACT}

This study is planned as an overall view in which a series of hypothesis are presented. As regards to the search of surviving and continuing elements during the Visigothic period in Hispania, the starting point are the "Etymologies" of Isidoro of Sevilla; although it is nearer to a transmission of an inherited culture and, thus, it has a value of erudition more than a testimonial, about the existence of a cult to waters. Another important source is the work De correctione rusticorum by Martin Dumiense, Bishop of Braga, which is referred to the survival of magical or supersti-

\footnotetext{
${ }^{45}$ Véase, además de la obra ya citada de J. R. Zaragoza, «Restos de la medicina clásica...", Op. cit., Lain EnTRalgo, P., La amistad entre el médico y el enfermo en la Edad Media, Discurso leído el 7 de junio de 1964 en la Real Academia de la Historia. Madrid 1964.
} 
cious believes; and also, some conciliar canons. Some spas are mentioned in use in Visigothic times. The study is completed with a section of other constructions and an appendix referred to curative waters and medical practice. 